\title{
Podocytes and the actin cytoskeleton as a feasible therapeutic target
}

\author{
SANJA SEVER * \\ CHANGKYU GU \\ Nephrology Division, Massachusetts General Hospital, \\ Charlestown, MA 02129, USA \\ *Correspondence: \\ Sanja Sever \\ ssever@mgh.harvard.edu \\ Keywords: Podocyte, Proteinuria, Chronic kidney \\ disease, Actin cytoskeleton
List of abbreviations:
GBM - Glomerular Basement Membrane
FPs - Foot Processes
CD2AP - CD2-Associated Protein
INF2 - Inverted Formin-2
DN - Diabetic Nephropathy
CKD - Chronic Kidney Diseases
GEF - GTP Exchange Factor
GAPs - GTPase Activating Proteins
GDI - GDP Dissociation Inhibitor
ROCK - Rho-associated Protein Kinase
ACE - Angiotensin Converting Enzyme
AR - Angiotensin Receptor
miRNAs - microRNAs
BDNF - Brain Derived Neurotrophic Factor
TrkB - Tropomyosin-Related Kinase B \\ FSGS - Focal Segmental GlomeruloSclerosis
}

Received October 03, 2016.

Revised November 15, 2016.

Accepted November 16, 2016

\begin{abstract}
Podocyte injury is a hallmark of the glomerular disease, which is a direct cause of chronic kidney diseases. Importantly, podocyte injury is a consequence of the dysregulation of the actin cytoskeleton. In diverse animal models of proteinuric glomerular disease, recovering the integrity of the actin structure in podocytes resulted in beneficial effects. In this review, we focus on the premise of targeting the actin cytoskeleton as feasible therapeutics for treating chronic kidney diseases.
\end{abstract}

\section{PODOCYTES AND THE MECHANISMS OF PROTEINURIA}

The selectivity of the glomerular filter is maintained by physical, 1 chemical, and signaling interplay among its three core constituents - the glomerular endothelial cells, the glomerular basement membrane (GBM), and podocytes (1). Injury to or functional impairment of any of these three components of the glomerular filtration barrier can lead to proteinuria (2). Podocytes are injured in many forms of human and experimental glomerular disease, including minimal change disease, focal segmental glomerulosclerosis (FSGS), and diabetes mellitus (3). Podocytes are terminally differentiated visceral epithelial cells of the glomerulus which develop a characteristic architecture specialized for glomerular ultrafiltration. Their structure is traditionally divided into three kinds of subcellular compartments: the cell body, microtubuledriven membrane extensions named primary process, and actin-driven membrane extensions named foot processes (FPs). Adjacent podocytes are interdigitated with each other at their foot processes, which are separated from each other by filtration slits and bridged with a specialized intercellular junction called a slit diaphragm. The foot processes and slit diaphragm serve as an adhesive apparatus to GBM, which together with endothelial cells and their glycocalyx form a filtration barrier.

Regardless of the underlying glomerular disease, the early pathogenic events are characterized by molecular alterations in the slit diaphragm without visible morphological changes or more obviously, by a reorganization of the FPs structure with fusion of filtration slits termed "FP effacement” (3-5). For over 50 years FPs effacement has been a cardinal feature of proteinuria. While the mechanistic significance of FP effacement with regard to proteinuria has long been a mystery, over the last decade numerous studies demonstrated that FP effacement represents a change in the organization of the actin cytoskeleton $(3,6)$.

The key findings that unequivocally established the role of the actin cytoskeleton in the maintenance of podocyte function were the identification of distinct genetic mutations that underlie hereditary forms of 
FSGS in proteins such as nephrin, CD2-associated protein (CD2AP), a-actinin 4, and inverted formin-2 (INF2) (7-11). In addition to distinct mutations, podocyte injury could also be multifactorial such as in diabetes or hypertension $(12,13)$. While mesangial cells were originally considered a major cell type in the glomerulus that underlies sclerosis in diabetic nephropathy $(\mathrm{DN})$, this is not exclusively true. Both podocytes and endothelial cells, and the crosstalk between all three glomerular cell types appear to play important roles in the evolution of diabetic glomerulosclerosis (14). A comprehensive approach to understanding pathologic features by analyzing of all three glomerular cell types is currently underway.

\section{ACTIN CYTOSKELETON DYNAMICS AS A PHARMACOLOGICAL TARGET IN KIDNEY DISEASES}

Actin cytoskeleton dynamics are regulated in time and space by a large number of signaling, scaffolding, and actin-binding proteins - a number of which have been linked to chronic kidney diseases $(\mathrm{CKD})(6,15)$. Given the close connection between podocyte structure and their function, it has been argued that targeting actin cytoskeleton dynamics might be a valuable strategy for treating $\mathrm{CKD}(5,16,17)$. Devising a strategy to directly target actin cytoskeleton in podocytes in a beneficial manner has been the major challenge.

Rho family GTPases are molecular switches best known for their pivotal role in regulation of the actin cytoskeleton $(18,19)$. The prototypic members of this family are Cdc42, Rac1, and Rho1. Although distinct, they function similarly to the heterotrimeric $\mathrm{G}$ proteins as they both change their conformations when bound to GTP and are switched off when GTP is hydrolyzed. GTP binding is facilitated by a GTP exchange factor (GEF), and hydrolysis is potentiated by GTPase activating proteins (GAPs). In their GTP bound state, G proteins bind and activate a wide variety of downstream effectors. A third regulator of small GTPases is called the GDP dissociation inhibitor (GDI) and functions to prevent the activation of the GTPase by blocking exchange. Several studies identified antagonism between RhoA and Racl GTPases in which activation of RhoA is almost always associated with the inactivation of Racl and vice versa.

The essential role of those small GTPases in kidney filtration was examined by Pawson and colleagues (20). Mice lacking Cdc42 in podocytes developed congenital nephropathy and died as a result of renal failure within 2 weeks after birth. In contrast, mice lacking Racl and RhoA in podocytes were overtly normal and lived to adulthood. Kretzler's group also generated podocytespecific deletions of Cdc42 and Racl, and observed similar phenotypes (21). Thus, the absence of Cdc 42 resulted in congenital nephropathy, whereas the absence of Racl had no effect on the development or the morphology of podocytes even after mice were monitored well into adulthood. Importantly, the deletion of Racl prevented protamine sulfate-induced FP effacement. However, in a chronic hypertensive damage model, the absence of Racl worsened proteinuria and sclerosis. This suggests that blocking Racl can function acutely to prevent FP effacement but after chronic injury, Rac1 is required for repair and a return to homeostasis. In complementary studies, Shaw and colleagues proposed that Racl activation underlies podocyte injury. Expression of Racl-GAP, Arhgap24, was found to be upregulated in podocytes as they differentiated both in vitro and in vivo. Mutation in $\mathrm{Ar}$ hgap24 that impairs its GAP activity, thus resulting in increase in the level of Racl:GTP, was associated with FSGS (22). Corroborating those original observations, induced expression of constitutively active Racl acutely caused FP effacement (23), whereas podocyte-specific deletion of Racl blocked foot process effacement and proteinuria induced by protamine sulfate (21). Together, these studies demonstrate that the actin cytoskeleton in podocytes is tightly regulated by balancing signaling pathways of multiple small GTPases.

Experimental data suggesting that targeting actin cytoskeleton in podocytes might be feasible and beneficial have been reported recently based on the effect of ROCK (Rho-associated protein kinase) inhibitors. ROCK is a major downstream effector of RhoA $(18,19)$, and inhibitors like Fasudil are approved for clinical use outside the US to treat pulmonary hypertension by attenuating vascular smooth muscle contraction $(24,25)$. ROCK inhibitors, such as Fasudil, Y27632, SAR407899 and statin, have been shown to attenuate proteinuria and interstitial fibrosis in many (rodent) models of diabetic nephropathy $(26,27), 5 / 6$ nephrectomy (28), nephrotoxic nephritis (29), UUO obstruction $(30,31)$, and ischemia reperfusion injury (32). Given such diverse models of kidney injury, it is not clear what is the target cell for the ROCK inhibitors and exactly how they work. Indeed, therapies that lower the blood pressure but that do not involve ROCK inhibition such are renin-angiotensin blockers, also show efficacy in attenuation of proteinuria (e.g. angiotensin converting enzyme (ACE) inhibitors and angiotensin receptor (AR) blockers) (33), suggesting that podocytes are not the direct target of those drugs. That said, use of ROCK inhibitors in clinic suggests that targeting actin cytoskeleton in a whole organism is a feasible approach.

In addition to the canonical GTPases mentioned above, the actin cytoskeleton in podocytes is also regulated by a large GTPase dynamin $(34,35)$. In contrast to small GTPases, dynamin does not require additional regulatory proteins such as GAPs, GEFs or GDIs since its GTPase cycle is regulated by its oligomerization cycle. The structure of the dynamin tetramer that consists of two dimers has been recently elucidated (36). Dynamin tetramers can oligomerize into partial and full rings or helices, and this oligomerization increases its GTPase ac- 
tivity due to the presence of the domain within dynamin itself that acts as intramolecular GAP (37). Dynamin has a relatively low affinity for both GTP and GDP (38), therefore release of GDP does not require presence of designated GEFs, nor is dynamin: GDP conformation stabilized by the presence of GDIs. A striking feature of dynamin assembly into higher order structures is the multitude of interactions in all four molecules (36). Structural data suggest that these contacts are not necessarily static, but characterized by a dynamic equilibrium of different binding conformations. It has been suggested that an assembly mode that involves many low-affinity interactions sites facilitates the reversibility of interactions and allows for the regulation of dynamin oligomerization, for example through nucleotide binding, hydrolysis or phosphorylation. Our recent study suggests that dynamin assembly presents an ideal pharmacological target as a proxy to target actin cytoskeleton dynamics (39). Another characteristic that distinguishes dynamin from canonical small GTPases is that dynamin directly binds actin filaments $(10,40)$. Dynamin-actin interactions promote GTP-dependent dynamin oligomerization, which releases capping protein gelsolin from the barbed ends resulting in the potent actin polymerization from the fast growing barbed ends and focal adhesion maturation (25). The molecular mechanism by which dynamin releases gelsolin from the barbed ends is at present unknown, but fluorescence lifetime imaging microscopy suggests that it requires GTP binding and a major conformational change within dynamin tetramers (40). The conformational change might be similar to the one suggested for dynamin assembly on the lipids $(36,40)$.

The physiological relevance for dynamin's role in regulating actin cytoskeleton has been demonstrated when mice expressing a dynamin mutant that promotes it to oligomerize specifically in podocytes exhibited unusually long FPs (39). Experiments using zebrafish further established the connection between dynamin-actin interactions, its oligomerization cycle, and function of podocytes by demonstrating that the expression of dynamin mutants impaired in either actin binding or assembly resulted in loss of high molecular weight protein from the circulation. In a complementary approach, administration of the small molecule Bis-T-23, which promotes actin-dependent dynamin oligomerization (40), and thus increases actin polymerization in injured podocytes, was sufficient to improve renal health in diverse models of both transient and chronic kidney injury. Specifically, Bis-T-23 restored the normal ultrastructure of foot processes, lowered proteinuria, lowered collagen IV deposits in the mesangial matrix, diminished mesangial matrix expansion, and extended lifespan. These findings for the first time showed the feasibility of targeting the actin cytoskeleton as therapeutics for CKD. Together, these data further underscore alterations in the actin cytoskeleton of kidney podocytes as a common hallmark of CKD, which could be pharmacologically altered by targeting dynamin oligomerization cycle.

Actin dynamics in podocytes are not only regulated by GTPases but also by microRNAs (miRNAs) (41). A study by Maria Pia Rastaldi and colleagues showed that Brain Derived Neurotrophic Factor (BDNF), a member of the neurotrophin family of polypeptide growth factors, binds the tropomyosin-related kinase $\mathrm{B}(\mathrm{TrkB})$ receptor on podocytes. BDNF binding resulted in a reduction of microRNA-134 and an increase in microRNA-132, which subsequently increased Limk1 translation and phosphorylation. Increase in Limk1 level increased cofilin phosphorylation, thus ultimately increasing the overall actin polymerization in podocytes. BDNF treatment profoundly reduced albuminuria in mouse adriamycin nephropathy with accompanied reforming of podocyte FPs. Together, the above studies provide compelling evidence that regardless of the upstream pathogenic factors that initiate podocyte injury (and because of multiple pathogenic pathways that cause podocyte injury), the actin cytoskeleton is a viable target in CKD.

Acknowledgement: This work was supported by $\mathrm{Na}$ tional Institute of Health (RO1 DK087985 to S. S.)

\section{REFERENCES}

1. Dimke H, Maezawa Y, Quaggin SE 2015 Crosstalk in glomerular injury and repair. Current opinion in nephrology and hypertension 24(3):231-8. https://doi.org/10.1097/mnh.0000000000000117

2. Haraldsson B, Nystrom J, Deen WM 2008 Properties of the glomerular barrier and mechanisms of proteinuria. Physiological reviews 88(2):451-87. https://doi.org/10.1152/physrev.00055.2006

3. Kerjaschki D 2001 Caught flat-footed: podocyte damage and the molecular bases of focal glomerulosclerosis. The Journal of clinical investigation 108(11):1583-7. https://doi.org/10.1172/JCI200114629

4. Reiser J, von Gersdorff G, Simons M, Schwarz K, Faul C, Giardino L, et al. 2002 Novel concepts in understanding and management of glomerular proteinuria Nephrology, dialysis, transplantation : official publication of the European Dialysis and Transplant Association - European Renal Association 17(6):951-5. https://doi.org/10.1093/ndt/17.6.951

5. Reiser J, Sever S 2013 Podocyte biology and pathogenesis of kidney disease. Annual review of medicine 64:357-66. https://doi.org/10.1146/annurev-med-050311-163340

6. Faul C, Asanuma K, Yanagida-Asanuma E, Kim K, Mundel P 2007 Actin up: regulation of podocyte structure and function by components of the actin cytoskeleton. Trends in cell biology 17(9):42837. https://doi.org/10.1016/j.tcb.2007.06.006

7. Santin S, Garcia-Maset R, Ruiz P, Gimenez I, Zamora I, Pena A, et al. 2009 Nephrin mutations cause childhood- and adult-onset focal segmental glomerulosclerosis. Kidney international 76(12): 1268-76. https://doi.org/10.1038/ki.2009.381

8. Shih NY, Li J, Karpitskii V, Nguyen A, Dustin ML, Kanagawa O, et al. 1999 Congenital nephrotic syndrome in mice lacking CD2associated protein. Science 286(5438):312-5. https://doi.org/10.1126/science.286.5438.312

9. Kaplan JM, Kim SH, North KN, Rennke H, Correia LA, Tong HQ, et al. 2000 Mutations in ACTN4, encoding alpha-actinin-4, cause familial focal segmental glomerulosclerosis. Nature genetics 24(3):251-6. https://doi.org/10.1038/73456 
10. Brown EJ, Schlondorff JS, Becker DJ, Tsukaguchi H, Tonna SJ, Uscinski AL, et al. 2010 Mutations in the formin gene INF2 cause focal segmental glomerulosclerosis. Nature genetics 42(1):72-6. https://doi.org/10.1038/ng.505

11. Boyer O, Nevo F, Plaisier E, Funalot B, Gribouval O, Benoit G, et al. 2011 INF2 mutations in Charcot-Marie-Tooth disease with glomerulopathy. The New England journal of medicine 365(25):237788. https://doi.org/10.1056/NEJMoa1109122

12. Pagtalunan ME, Miller PL, Jumping-Eagle S, Nelson RG, Myers BD, Rennke HG, et al. 1997 Podocyte loss and progressive glomerular injury in type II diabetes. The Journal of clinical investigation 99(2):342-8. https://doi.org/10.1172/JCI119163

13. Endlich N, Endlich K 2012 The challenge and response of podocytes to glomerular hypertension. Seminars in nephrology 32(4):32741. https://doi.org/10.1016/j.semnephrol.2012.06.004

14. Reidy K, Kang HM, Hostetter T, Susztak K 2014 Molecular mechanisms of diabetic kidney disease. The Journal of clinical investigation 124(6):2333-40. https://doi.org/10.1172/JCI72271

15. Pavenstadt H, Kriz W, Kretzler M 2003 Cell biology of the glomerular podocyte. Physiological reviews 83(1):253-307. https://doi.org/10.1152/physrev.00020.2002

16. Durvasula RV, Shankland SJ 2006 Podocyte injury and targeting therapy: an update. Current opinion in nephrology and hypertension 15(1):1-7. https://doi.org/10.1097/01.mnh.0000199012.79670.0b

17. Tian X, Ishibe S 2016 Targeting the podocyte cytoskeleton: from pathogenesis to therapy in proteinuric kidney disease. Nephrology, dialysis, transplantation : official publication of the European $\mathrm{Di}$ alysis and Transplant Association - European Renal Association. 31(10):1577-83. https://doi.org/10.1093/ndt/gfw021

18. Jaffe AB, Hall A 2005 Rho GTPases: biochemistry and biology. Annual review of cell and developmental biology 21:247-69. https://doi.org/10.1146/annurev.cellbio.21.020604.150721

19. Spiering D, Hodgson L 2011 Dynamics of the Rho-family small GTPases in actin regulation and motility. Cell adhesion \& migration 5(2):170-80. https://doi.org/10.4161/cam.5.2.14403

20. Scott RP, Hawley SP, Ruston J, Du J, Brakebusch C, Jones N, et al. 2012 Podocyte-specific loss of Cdc42 leads to congenital nephropathy. Journal of the American Society of Nephrology : JASN 23(7):1149-54. https://doi.org/10.1681/ASN.2011121206

21. Blattner SM, Hodgin JB, Nishio M, Wylie SA, Saha J, Soofi AA, et al. 2013 Divergent functions of the Rho GTPases Racl and Cdc42 in podocyte injury. Kidney international 84(5):920-30. https://doi.org/10.1038/ki.2013.175

22. Akilesh S, Suleiman H, Yu H, Stander MC, Lavin P, Gbadegesin R, et al. 2011 Arhgap24 inactivates Rac1 in mouse podocytes, and a mutant form is associated with familial focal segmental glomerulosclerosis. The Journal of clinical investigation 121(10):4127-37. https://doi.org/10.1172/JCI46458

23. Yu H, Suleiman H, Kim AH, Miner JH, Dani A, Shaw AS, et al. 2013 Rac1 activation in podocytes induces rapid foot process effacement and proteinuria. Molecular and cellular biology 33(23):4755-64. https://doi.org/10.1128/MCB.00730-13

24. Shi J, Wei L 2013 Rho kinases in cardiovascular physiology and pathophysiology: the effect of fasudil. Journal of cardiovascular pharmacology 62(4):341-54.

https://doi.org/10.1097/FJC.0b013e3182a3718f

25. Feng Y, LoGrasso PV, Defert O, Li R 2016 Rho Kinase (ROCK) Inhibitors and Their Therapeutic Potential. Journal of medicinal chemistry 59(6):2269-300.

https://doi.org/10.1021/acs.jmedchem.5b00683

26. Komers R, Oyama TT, Beard DR, Tikellis C, Xu B, Lotspeich DF, et al. 2011 Rho kinase inhibition protects kidneys from diabetic nephropathy without reducing blood pressure. Kidney international 79(4):432-42. https://doi.org/10.1038/ki.2010.428

27. Komers R 2013 Rho kinase inhibition in diabetic kidney disease. British journal of clinical pharmacology 76(4):551-9. https://doi.org/10.1111/bcp.12196

28. Babelova A, Jansen F, Sander K, Lohn M, Schafer L, Fork C, et al. 2013 Activation of Rac-1 and RhoA contributes to podocyte injury in chronic kidney disease. PLoS one8 (11):e80328. https://doi.org/10.1371/journal.pone.0080328

29. Christensen M, Su AW, Snyder RW, Greco A, Lipschutz JH, Madaio MP 2006 Simvastatin protection against acute immune-mediated glomerulonephritis in mice. Kidney international 69(3):45763. https://doi.org/10.1038/sj.ki.5000086

30. Nagatoya K, Moriyama T, Kawada N, Takeji M, Oseto S, Murozono T, et al. 2002 Y-27632 prevents tubulointerstitial fibrosis in mouse kidneys with unilateral ureteral obstruction. Kidney international 61(5):1684-95. https://doi.org/10.1046/j.1523-1755.2002.00328.x

31. Satoh S, Yamaguchi T, Hitomi A, Sato N, Shiraiwa K, Ikegaki I, et al. 2002 Fasudil attenuates interstitial fibrosis in rat kidneys with unilateral ureteral obstruction. European journal of pharmacology 455(2-3):169-74. https://doi.org/10.1016/S0014-2999(02)02619-5

32. Kentrup D, Reuter S, Schnockel U, Grabner A, Edemir B, Pavenstadt H, et al. 2011 Hydroxyfasudil-mediated inhibition of ROCK1 and ROCK2 improves kidney function in rat renal acute ischemiareperfusion injury. PLoS one 6(10):e26419. https://doi.org/10.1371/journal.pone.0026419

33. Remuzzi G, Perico N, Macia M, Ruggenenti P 2005 The role of renin-angiotensin-aldosterone system in the progression of chronic kidney disease. Kidney international Supplement (99):S57-65. https://doi.org/10.1111/j.1523-1755.2005.09911.x

34. Sever S, Altintas MM, Nankoe SR, Moller CC, Ko D, Wei C, et al. 2007 Proteolytic processing of dynamin by cytoplasmic cathep$\sin \mathrm{L}$ is a mechanism for proteinuric kidney disease. The Journal of clinical investigation 117(8):2095-104 https://doi.org/10.1172/JCI32022

35. Soda K, Balkin DM, Ferguson SM, Paradise S, Milosevic I, Giovedi S, et al. 2012 Role of dynamin, synaptojanin, and endophilin in podocyte foot processes. The Journal of clinical investigation 122(12):4401-11. https://doi.org/10.1172/JCI65289

36. Reubold TF, Faelber K, Plattner N, Posor Y, Ketel K, Curth U, et al. 2015 Crystal structure of the dynamin tetramer. Nature 525(7569):404-8. https://doi.org/10.1038/nature14880

37. Sever S, Muhlberg AB, Schmid SL 1999 Impairment of dynamin's GAP domain stimulates receptor-mediated endocytosis. Nature 398(6727):481-6. https://doi.org/10.1038/19024

38. Binns DD, Helms MK, Barylko B, Davis CT, Jameson DM, Albanesi JP, et al. 2000 The mechanism of GTP hydrolysis by dynamin II: a transient kinetic study. Biochemistry 39(24):7188-96. https://doi.org/10.1021/bi000033r

39. Schiffer M, Teng B, Gu C, Shchedrina VA, Kasaikina M, Pham VA, et al. 2015 Pharmacological targeting of actin-dependent dynamin oligomerization ameliorates chronic kidney disease in $\mathrm{di}-$ verse animal models. Nature medicine 21(6):601-9. https://doi.org/10.1038/nm.3843

40. Gu C, Chang J, Shchedrina VA, Pham VA, Hartwig JH, Suphamungmee W, et al. 2014 Regulation of dynamin oligomerization in cells: the role of dynamin-actin interactions and its GTPase activity. Traffic 15(8):819-38. https://doi.org/10.1111/tra.12178

41. Li M, Armelloni S, Zennaro C, Wei C, Corbelli A, Ikehata M, et al. 2015 BDNF repairs podocyte damage by microRNA-mediated increase of actin polymerization. The Journal of pathology 235(5):731-44. https://doi.org/10.1002/path.4484 